\title{
Mothering, Albinism and Human Rights: The Disproportionate Impact of Health-Related Stigma in Tanzania
}

\author{
Sheryl Reimer-Kirkham ${ }^{1}$ D $\cdot$ Barbara Astle ${ }^{1} \cdot$ Ikponwosa Ero $^{2,3} \cdot$ Elvis Imafidon ${ }^{4}$ \\ Emma Strobell ${ }^{1}$
}

Received: 18 January 2020 / Revised: 22 August 2020 / Accepted: 2 September 2020 /

Published online: 8 October 2020

(c) The Author(s) 2020

\begin{abstract}
In many parts of sub-Saharan Africa, mothers impacted by the genetic condition of albinism, whether as mothers of children with albinism or themselves with albinism, are disproportionately impacted by a constellation of health-related stigma, social determinants of health (SDH), and human rights violations. In a critical ethnographic study in Tanzania, we engaged with the voices of mothers impacted by albinism and key stakeholders to elucidate experiences of stigma. Their narratives revealed internalized subjective stigma, social stigma such as being ostracized by family and community, and structural stigma on account of lack of access to SDH. An analysis of health systems as SDH revealed stigmatizing attitudes and behaviours of healthcare providers, especially at the time of birth; a lack of access to timely quality health services, in particular skin and eye care; and a lack of health-related education about the cause and care of albinism. Gender inequality as another SDH featured prominently as an amplifier of stigma. The findings pose implications for research, policy, and practice. A concrete avenue to de-stigmatization of mothers impacted by albinism exists by the application of principles of human rights, particularly equality and non-discrimination; contextual analysis of cultural dynamics including relevant ontology; meaningful participation of rights-claimants, such as peer groups of mothers; and accountability of governments and their obligation to ensure access to health information as a key social determinant of the right to health.
\end{abstract}

Keywords Albinism - Stigma · Human rights · African ontology · Ethnography · Gender · Social determinants of health $\cdot$ Gender equality $\cdot$ Equity $\cdot$ Mothers

Sheryl Reimer-Kirkham

sheryl.kirkham@twu.ca

1 Trinity Western University, Langley, Canada

2 United Nations Independent Expert on the Enjoyment of Human Rights by Persons with Albinism, Geneva, Switzerland

3 Under the Same Sun, Surrey, Canada

4 University of London, London, England, UK 


\section{Introduction}

Stigma is associated with a range of health conditions and social situations, often resulting in negative health and social effects. Such is the case with albinism, a relatively rare, non-contagious genetically inherited condition (Kromberg and Manga 2018; Kromberg et al. 2020) that causes a lack of melanin in the skin, hair and eyes. Albinism occurs worldwide, at a rate of about 1 in 17,000, but the incidence rises as high as 1 in 1000 in parts of Africa (Gronskov et al. 2007; Hong et al. 2006). Physiological effects of albinism such as visual impairment, once established, and skin vulnerability to disfiguring solar damage are bases of additional negative social and health consequences. On account of their appearance, and fueled by superstitions and beliefs about albinism, persons with albinism often face discrimination in the form of social ostracism (Brocco 2016; Burke 2015). In some regions of Africa, persons with albinism have been subjected to violent attacks, with their body parts sold on the black market (Brilliant 2015; International Federation of Red Cross and Red Crescent Societies 2009; United Nations General Assembly (UNGA) 2017a, 2019a).

In this paper we present an analysis of mothers' experiences of stigma, drawing on a critical ethnography on mothering, albinism, and human rights that is underway in Tanzania, and will continue in South Africa, and Ghana. We selected Tanzania as a study site because of its relatively high incidence of albinism and also as a region that has seen numerous attacks and threats against persons with albinism. Owing in large part to this history of violence, the incidence of albinism in Tanzania is believed to be largely underestimated due to fears of self-identifying in a census, as well as the challenge of gathering data from the most rural areas of the country (de Groot et al. 2019; Lund and Roberts 2018; UNGA 2017a). According to the National Bureau of Statistics, in the 2012 census 16,477 (1 in 2673) people reported albinism, which is recognized as a disability in Tanzania (The United Republic of Tanzania 2014, 2016). Under the Same Sun (n.d.), an albinism advocacy and education organization, estimates the incidence to be much higher at 1 in 1400 people, or over 33,000 people with albinism. Tanzania is described as a country where spiritualized cosmologies infuse political, economic, and private spheres of life, and where the religions of its colonizers - Christianity and Islam — are increasingly indigenized (Imafidon 2018; Olupona 2014). Tanzania achieved independence in 1961 through relatively peaceful processes but its development is undermined by persistent poverty and sharp inequalities, including urban and rural differences and gender imbalances (Mtenga et al. 2016). Patriarchal norms suppress many women in Tanzania, especially those impacted by little-known disabilities such as those related to the condition of albinism (Nyangweso and Olupona 2020; UNGA 2016). The findings of our study give insight into the interplay of healthrelated stigma, lack of access to the social determinants of health $(\mathrm{SDH})$, and human rights violations, which differentially disadvantage mothers impacted by albinism.

\section{Background and Literature Review}

Goffman (1963, p. 13) described stigma as “... an attribute that is deeply discrediting, and is socially constructed on the basis of what society regards as being different or deviant." According to Goffman (1963), this attribute and social response reduces the bearer "from a whole and usual person to a tainted, discounted one" (p. 3). Building on Goffman's work, 
Link and Phelan $(2001,2006)$ conceptualize stigma as a process with five interrelated components: the social selection process determining and labelling which differences are deemed relevant and consequential; stereotyping whereby the labelled person is linked to undesirable characteristics; separating those with the labelled social difference as "other"; enacting discrimination and loss of status against those who are "other"; and the exercise of power.

\subsection{Health-Related Stigma}

A rich body of scholarship exists around health-related stigma relative to disabilities and chronic illnesses (e.g., Clement et al. 2015; Corrigan 2014; Stangl et al. 2013). Common themes across these fields point to subjective, social, and structural aspects of stigma. Mechanisms of health-related stigma include behavior change because of feeling judged (e.g., avoiding help-seeking); psychosocial stress on account of feeling stigmatized; social network changes based on stigmatizing actions and decisions by others; and structural effects of stigma. Despite the extensive documentation of the health effects of stigma, progress has stalled in our collective ability to tackle stigma and its harmful consequences (Stangl et al. 2019). Especially in the fields of health and psychology, stigma has tended to be studied at the individual level with single domain interventions, even though it is a multi-leveled phenomenon. In the African context, such an individualistic reading may not align with the relational, communal worldviews that inform much of life (Imafidon 2017). One framework that guides an expanded analytic approach is the Health Stigma and Discrimination Framework, developed by Stangl et al. (2019), as a crosscutting framework based on research, practice and theory with demonstrated applicability to a variety of health conditions, and uptake in research, programming, and policy efforts. This framework makes visible how stigma operates at the individual level as a barrier to health seeking behaviour, engagement in care, and adherence to treatment, and importantly how broader social, cultural, political, and economic forces structure stigma. In this paper, we provide such a multi-level analysis, drawing SDH and human rights into our analysis of health-related stigma, with the overarching aim to address health inequalities for mothers impacted by albinism.

\subsection{Stigma and Social Determinants of Health}

As structural aspects of stigma have become more widely understood, the links between stigma and health inequalities are being recognized (Hatzenbuehler 2016). The seminal 2008 report by the WHO Commission on the Social Determinants of Health (CSDH) describes how the SDH should have health equity ${ }^{1}$ as their priority. Stated simply, SDH address avoidable inequities in health arising because of where people live, work, grow,

\footnotetext{
1 Equity as defined by the WHO (2020): "is the absence of avoidable or remediable differences among groups of people, whether those groups are defined socially, economically, demographically, or geographically. Health inequities therefore involve more than inequality with respect to health determinants, access to the resources needed to improve and maintain health or health outcomes. They also entail a failure to avoid or overcome inequalities that infringe on fairness and human rights norms (para. 1). As related to equality, equity is generally understood as a process focused on fairness, whereby particular attention is paid to those at greatest risk of poor health, whereas equality is understood as an indicator of sameness or the degree to which people achieve similar health and social outcomes (Blanchet Garneau et al. 2019).
} 
and age, and the systems put in place to handle illness (WHO CSDH 2008). Key SDH that influence persons with albinism are gender, income and social status, education, health systems, and access to services (WHO CSDH 2008). Stigma can rob people labeled "ill" of their right to equal opportunities relative to health care, housing, employment, friends, faith-based communities, and legal protections (Corrigan 2014). As a result, the health outcomes of a person and population are related to the structural determinants and conditions of daily life that comprise the SDH and are responsible for the majority of health inequities between and within countries (UN Economic and Social Council (UNECOSOC) 2000).

Mtenga et al. (2016) studied how strengthening SDH was important for addressing health inequities in Tanzania, as there are significant discrepancies within urban and rural areas with a direct impact on access to health care. They found that the majority of research in Tanzania fails to consider the context-specific structural determinants of health and inequities that provide a broader understanding of existing vulnerabilities. As a result, they concluded that establishing a system that promotes collaboration amongst sectors and strengthens collective capacities for institutions and individuals researching SDH are important to better inform intersectoral polices and SDH research initiatives.

In 2000, the United Nations (UN) introduced the Millennium Development Goals (MDGs) which improved the lives of many. Despite this progress, the inequalities between countries widened (UNGA 2015). This widening gap led to the adoption of the Sustainable Development Goals (SDGs) in 2015, with a focus on health equity and the SDH to address the inequalities between nations, and within nations (UNGA 2015). The SDGs currently govern the global development agenda and seek to realize human rights for all including the right to health (UNGA 2015). Goal number 3 of the SDGs addresses health as a central place for the promotion of well-being for everyone, "leaving no one behind" (UN 2015). Inequities arise when certain persons or populations receive advantages and others do not. Therefore, when one person or population is unreasonably advantaged over another, other mechanisms are required to be put in place, such as a human rights framework that holds governments accountable for harmful SDH (Stronks et al. 2016). Stronks et al. (2016) argue that "given the moral arguments for the injustice of health inequalities, human rights might invite and encourage governments to take action to tackle health inequalities" (p. 11). Furthermore, the intersection of SDH and human rights enable one to better respond and understand the depth of power differentials and structural disparities that impact health (Kenyon et al. 2018).

\subsection{Stigma and Albinism in African Contexts}

A range of stigmatizing beliefs and practices related to albinism have been reported in Africa. Persons with albinism may face labelling and name-calling (Baker et al. 2010; Brocco 2015, 2016; Cruz-Inigo et al. 2011; Possi 1998), for example, being referred to as "white goats" (mbuliwmelu), "ghosts" (zeru zeru) or "white people" (mzungu). Stigma can extend to social avoidance and exclusion, and being treated disrespectfully when accessing education, health, or social services. A scoping review on albinism, spiritual and cultural practices, and human rights (Reimer-Kirkham et al. 2019) noted that mental health concerns (including loss of self-esteem, depression, isolation, suicide; see Attama et al. 2015; Mutasa 2013; Phatoli et al. 2015) occur as a result of stigma and discrimination associated with this condition. Also reported is how stigma results in difficulty in access to social and health services (Mutasa 2013; Salewi 2011). Persons with albinism possess feelings of being stigmatized and easily identified, and so 
did not access, for example, antiretroviral treatments that they require (Aluko-Olokun et al. 2016; Okoro 1975). These cumulative effects of stigma reduce overall quality of life (Affram et al. 2019; Attama et al. 2015; Kiprono et al. 2012). In addition, the impact of stigma has been studied in various countries and population groups, such as children and young people with albinism in Uganda, (Bradbury-Jones et al. 2018; Brocco 2015; Franklin et al. 2018; Kromberg et al. 2020), but only one study foregrounded as primary sample mothers impacted by albinism (Kromberg et al. 1987). Stigmatizing beliefs have also played a role in fueling violent attacks, mutilations, and murders of persons with albinism where it is thought that their body parts, organs, hair, and nails hold supernatural powers when used to make charms by diviners or witchdoctors for those willing to buy (Aquaron et al. 2009; Brocco 2015; Cruz-Inigo et al. 2011; Imafidon 2017). Women and children are disproportionately subject to such violent attacks (Ojilere and Saleh 2019; UNGA 2019a).

Stigmatizing beliefs and practices related to albinism in African communities, especially where counter-narratives have not been well established, are deeply-rooted into the fabric of society and justified by the understanding of being or reality, or by the ontology operational in such communities or societies (Imafidon 2017; Imafidon 2019). Generally, African ontology can be understood as the African theory of being, of what is and what is not, which includes the theory of the being of a person (that is what a person should be composed of). Within this theory of being, certain categories of human beings are excluded from being human; the list of such beings may vary from place to place but includes persons with kyphosis, persons with dwarfism, twins, persons with albinism, and other forms of the composition of the human being that go beyond the norm. When understood as not being human, persons with albinism are unable to enjoy the same rights and privileges that persons who fit within the ontological norm of being human enjoy, and these predominantly are the melanin-privileged Africans. If persons with albinism are considered to be white goats, ghosts, apes, or beings that simply varnish and do not die (Muromi 2014), then it can seem justified or acceptable within this ontological framework that such beings are not treated as human and, by implication, are stigmatized.

\subsection{Human Rights, Albinism, and Stigma}

Parker (2012) notes that a human rights focus applied to stigma and its resultant human suffering is a relatively new approach. This approach to stigma occurs in the context of HIV and AIDS in which human rights are often violated in the enactment of stigma (Maluwa et al. 2002). These human rights abuses can originate from governments, private organizations, and institutions, as well as from communities, families, and individuals. Maluwa et al. (2002) explain that freedom from discrimination is in and of itself a human right, "which brings into play an existing framework of responsibility and accountability for state action" (p. 9). A human rights framework provides access to existing procedural, institutional, and other monitoring mechanisms that should not only enforce the rights of people living with HIV and AIDS (similarly for the case of persons with albinism), but should also counteract and redress discriminatory action. A significant gap in the literature exists, however, as little research applies these vital, interlocking concepts to albinism, and especially so for mothers. In this paper, we undertake a multidisciplinary analysis to begin to address this gap. 


\section{Describing the Study}

The purpose of this critical ethnographic study is to explore through a human rights lens the resilience of mothers impacted by albinism, at the intersection of gender and religion (SSHRC \#435-2019-1120, 2019-2023). Extending ethnography's study of people and cultures, critical ethnography as method gives particular attention to "raising consciousness and aiding emancipatory goals in the hope of affecting social change" (Polit and Beck 2017, p. 480). The study objectives are to:

1 Examine the everyday lives of mothers impacted by albinism relation to residence, security and well-being, and parenting and provision for their families.

2 Describe how mothers and their children impacted by albinism access community services, such as social and health services, education, and employment.

3 Explore social constructions of gender and colourism in relation to albinism in the contexts of Tanzania, and their impact on the experience of mothering.

4 Analyze how the spiritual/cultural beliefs and practices impact on the experience of mothering and albinism.

5 Articulate recommendations for the protection and promotion of the human rights of these mothers and their children.

The study involves participatory fieldwork in Tanzania, South Africa, and Ghana. The Canadian Coalition for Global Health Research (2015) principles for global health research guide the partnering process between the research sites and researchers in this study. Research ethics clearance was obtained from the researchers' university in Canada; in Tanzania from the National Institute of Medical Research (NIMR) and COSTECH (Tanzania Commission for Science and Technology).

We recruited participants through convenience and purposeful sampling by collaborating with a local nongovernmental organization (NGO); and other local and international key informants from Dar es Salaam and the Mwanza region in Tanzania, representing both urban and rural experiences. During two field visits, lasting six and four weeks respectively, we interviewed 62 participants (36 key informants and 26 mothers), either individually or in sharing circles. Key informants included four participants with albinism (three female and one male) and 32 without albinism, 19 females and 17 males, and aged between 21 and 60. This sub-sample included a social worker, a journalist, a policy maker, a school matron, two researchers, four NGO staff, four teachers, four nurses, and 18 faith leaders. The sub-sample of mothers included those with albinism themselves $(n=9)$, as well as those who have children with albinism $(n=17)$. Mothers were aged between 21 and 80 years old with the majority $(n=10)$ between 31 and 40 . A variety of ages were represented by their children with albinism from six-months old to over 30 . Twelve mothers lived in an urban location while 14 lived in more rural settings. Nineteen mothers identified as Christian, and seven as Muslim; none self-identified as affiliated with African Traditional Religion, although some described beliefs and practices typically associated with this tradition, suggesting hybrid spiritual identities.

Ethnographic data collection consisted of sharing circles (akin to focus groups), indepth semi-structured interviews (lasting 1 to 2 hours), and participant observation. Sharing circles and interviews were conducted in Kiswahili with a cultural liaison who interpreted between Kiswahili and English, and were digitally recorded. Each recording was transcribed, in English, by a transcriptionist with data stored on a password protected 
computer to ensure confidentiality and data integrity. Ethnographic data also included extensive field notes and reflexive journaling.

We employed qualitative methods of data analysis, with multiple readings of the data accompanied by ethnographic writing. Facilitated by $\mathrm{NVivo}^{\mathrm{TM}}$, we generated a codebook through line-by-line coding, followed by clustering categories into themes for increasing levels of abstraction into a final coherent analytic narrative. The Canadian and Tanzanian team members joined in a data analysis intensive to validate and extend the preliminary findings through consultation and interpretation. This same consultation process was conducted with mothers who participated in the study.

Lincoln and Guba's (1985) five criteria for developing trustworthiness were employed. Through prolonged engagement and immersion in the field, ongoing member checking, researcher reflexivity (Jootun et al. 2009), and knowledge exchange with our partners, credibility was achieved. An audit trail to track ongoing decision in the research process, and theoretical and data triangulation achieved the criteria of dependability. Confirmability was achieved by ongoing dialogue with local research partners, and by follow-up sharing circles for validation during the second fieldwork visit. Transferability of the findings was accomplished through thick description to facilitate the transfer of findings to other regions in sub-Saharan Africa. Finally, authenticity was achieved by using verbatim quotes, rich description from field notes, and ensuring the voices of participants remain central to each phase of analysis and writing.

\section{Findings}

The findings of this study reveal the disproportionate effect of health-related stigma on mothers impacted by albinism (whether themselves persons with albinism, or as mothers of children with albinism) as an overarching theme. We describe the everyday experience of this stigma by drawing on firsthand accounts of mothers and various stakeholders who add detail and perspective. The data revealed deepened lines of income and health inequities as a result of stigma, exacerbated by weak SDH and human rights violations. For the mothers in our study, targeted interventions such as peer groups of mothers (known as mamas' groups) and rural health education mitigated the effects of stigma and SDH, and offered protection against violent attacks.

\subsection{Learning About Everyday Stigma from Mothers Impacted by Albinism}

Serving as entry point to our presentation of findings, Tishala (pseudonym), a Tanzanian mother of children with albinism from a rural setting, shared with us her daily experience of stigma, co-occurring at several levels. Her experiences were echoed by other mothers and stakeholders in the study. In the description of findings that follow, we show how stigma was particularly pronounced at the time of birth, in the contexts of family and community relations, and could be mitigated by mamas' groups.

\subsubsection{Expressions of Stigma by Healthcare Providers at the Time of Birth}

Tishala and her husband were about to have their first child. As her baby emerged, she could hear the nurses chattering amongst themselves: "What is this?"; "What has she delivered?"; "Why is your baby so light?" He had white hair and white skin, but 
was crying vigorously and otherwise looked healthy. Even the nurse did not know why he was so light: "Maybe he will turn colour after a while."

This reaction from healthcare providers upon delivery of a child with albinism was commonplace amongst participants. Of 17 mothers without albinism themselves, only two spoke of positive experiences at the time of delivery. Mothers recalled hearing nurses whisper, express shock and fear, run away or even scream in alarm. For example, Amana (pseudonym) described the accusations she faced by nurses in the delivery room: "AAre you sure you didn't sleep with a white man?'... I was seen as very evil and promiscuous.” Similarly, Asha's (pseudonym) described stigmatization by nurses in the delivery room who refused to touch, weigh, dress, or carry her baby. She was abandoned, left to manage on her own. Based on this, Asha added, "I didn't ask anything from them anymore," a sentiment shared by other mothers describing their interactions with healthcare providers following delivery.

In a subsequent interview with nurses from a rural hospital, we learned that they had recently received education from a local albinism society. Sakina (pseudonym), explained: "The awareness training that we had last week was very good. People with albinism were doing the teaching. So you see, it was them saying 'Treat us this way."' Sakina's comments affirm the effectiveness of albinism education delivered by those who themselves have albinism in breaking down stigma. This education that enabled healthcare providers to understand albinism facilitated a process of de-stigmatization in which healthcare providers were better equipped to provide ethical care to patients who are impacted by albinism. Sakina described an initiative to ensure mothers and their families are taught about albinism,

As nurses, we ask them first if this is their first baby with albinism and if it is, we go deeper to explain what albinism is to the mother. If she has a spouse, they call [him] and do the basic albinism awareness and ... eventually you also engage the relatives who are in hospital so that they understand that this child can be born to me or any other person or even you.

The education described by Sakina is what Tishala noted as missing in her own experience. This gap was echoed by all 17 of the mothers without albinism we interviewed; not a single woman reported leaving the hospital equipped with the key information about albinism and how to care for her child(ren). This finding points to the need for urgent expansion of education for healthcare providers.

\subsubsection{Experiences of Stigma in the Context of Family and Community}

Returning to Tishala's narrative, she was discharged home with no education or information about why her child's colour was different from that of his parents.

Her husband was perplexed, "What is this you have delivered?" He hoped that, as the nurse said, after some time, "he would turn colour." His mother-in-law told him that Tishala had been very light when she was born, "don't worry, he will become darker." But when Tishala's mother came to see her grandchild: "Ah, no. Her lightness was not like this. This must be a zeru zeru." They struggled to figure out "which side" this coloring came from, but neither could identify any persons with albinism in their lineage.

Over time, Tishala noticed that when her son with albinism was in the sun for too long, he would develop sores on his skin. She started to apply lotion and oilsboiling the cooking oil first, letting it cool, and then applying it to his skin. She 
felt this helped, but still did not understand her son's condition. It was not until six years later that a team of people (Tishala was not able to recall where they were from, likely an NGO CSO) came to her village, a meeting was called, and the community was taught about albinism. She was told about sunscreen and where she could get some in the nearby town.

A lack of knowledge about albinism, its genetic cause, and the required skin and vision care is evident in Tishala's story. Notably, the lapse in time from delivery of Tishala's child with albinism to receiving health information on albinism was echoed by several mothers, as was the trial and error approach to caring for their child's particular needs. As illustrated in the responses of Tishala's family, lack of knowledge on albinism was common in her region, and resulted in other stigmatizing knowledges coming into play.

Most mothers who birthed children with albinism spoke of being accused of having an affair or conceiving during menstruation (something that invites misfortune within this context). They reported denial of paternity, violence, and abandonment. To illustrate, Imara (pseudonym), a single mother of six girls, three with albinism, spoke of the immediate accusations by her husband: "What is this you have delivered? Did you sleep with an albino?" These accusations developed into physical abuse by her husband upon the delivery of her next daughter with albinism and cemented her position as sole caregiver and provider.

When attacks against persons with albinism in surrounding areas were on the rise, Tishala brought her son to a government holding centre, a 4 hour bus-ride away, to ensure his safety. At this time she was pregnant with their second child. Upon delivery of another son with albinism, Tishala said:

But now the father, he was the saddest man. When he went back home and his family asked what baby has been born he said, "Ah, the same type of kids that she delivers." It started the back and forth of family meetings, trying to excommunicate me because I'm not a woman enough and they can't continue keeping me, I'm defiling their lineage. I can't deliver proper kids. Eventually they took me back to my parents' home.

Without support from her husband, resisting the internalized stigma of "not being woman enough", and living within the context of poverty, Tishala collected fruit and sold it at roadside markets to support her family - all while trying to keep her young son with albinism safe from attackers. She had to take him everywhere with her. With minimal education herself and a community believing her children were cursed because of something that she had done wrong, she experienced the effects of social stigma in her everyday including being isolated from her community and the support of her nuclear and extended family.

Women with albinism themselves $(n=9)$ also described profoundly stigmatized experiences. Zahara (pseudonym) told of the social stigma experienced when community members asserted that those with albinism are not capable of anything, with comments such as: "you can't do this, you can't do that... 'you can't cook,' 'this one cannot even give birth." Highlighting the gendered stigma she experienced daily, she explained how men are curious: "how is she to sleep with? So they will try getting into a relationship with you... and you accept that. They will sleep with you [and] go tell others." Zahara articulated the visceral impact to dignity she experienced as gossip infiltrated her small community: "you see from the beginning they were just coming to see how you are... So even as you walk, people know how you are-your dignity is shattered." Facing devastating circumstances, she was left to support her family. 
Mothers in this study acknowledged the vast differences generally experienced between mothers and fathers in Tanzania, even apart from albinism. Participants noted that women are the key figures in any household, bearing the burden of childbearing, childrearing, and maintaining the overall household. When asked what the differences are between how mothers and fathers of children with albinism are viewed and how this impacts raising their children, Tishala stated:

There's a big, big difference. You see, most of the fathers are absent fathers. Look at my case. We are no longer together with that man. If I am not empowered to be able to stretch myself to meet the needs of my child then it is my child who will suffer. Even when I get married to another family I go with my child even when I know clearly that child might not be accepted here.

Thus, in a patriarchal society where women already carry household and childrearing responsibilities, mothers impacted by albinism were made even more vulnerable through the impact of stigma.

\subsubsection{Mamas' Groups as Mitigating Stigma}

Important to these narratives of stigma were those community resources that mitigated the impacts of stigma. Tishala noted that the support she received through a mamas' group facilitated by NGOs made a substantial difference. She explained that it was a place where she related with other women, learned various skills (e.g., making candles and beeswax wraps, and managing finances, business operations and customer service), and earned a more consistent income, adding, "If you empower women, you've empowered the household." The other 20 mothers who participated in such groups described them as the singular space where they feel fully accepted and empowered, a reprieve from social stigma in their day to day. In a sharing circle, one mother said, "The things we've been doing as a group have earned us respect in our society because this group is a classic example that if you empower us, we are capable" (Sharing Circle 3, Participant). NGOs and stakeholders whom we interviewed explained that although the majority of their time and resources were going to children with albinism, they had come to recognize the plight of women and mothers impacted by albinism. They identified that mothers, who experienced such stigma in their everyday, needed a place of acceptance, support, and championing. In one site they found Sarah (pseudonym) to facilitate a mamas' group. Sarah recognized the mamas' potential and fostered the development of a community of women impacted by albinism who learnt a profitable trade, experiencing sisterhood and the acceptance that comes with that.

These narratives provide ample evidence of the everyday experience of stigma by mothers impacted by albinism. The experiences of Tishala and others like her situate this stigma in what are already constrained life circumstances, and show how targeted interventions such as health education and mamas' groups can mitigate stigma and its effects. In the following discussion, we examine how these experiences of stigma can be better understood through the analytic lenses of SDH and human rights. 


\section{Discussion: Stigma, Social Determinants of Health and Human Rights}

\subsection{Stigma and the Social Determinants of Health}

The experiences of mothers impacted by albinism in Tanzania draw attention to the SDH as the stage where stigma plays out. Particularly stark are intersections of stigma with the SDH of health systems and gender inequality. The data suggest that for mothers impacted by albinism, stigma acts as an accelerator or amplifier of these SDH already at play. Therefore, their individual experiences of stigma must be understood in the context of structuring forces such as the social determinants of health.

\subsubsection{Health Systems as a Social Determinant of Health}

Analysis of our findings showed health systems (including access to health education and services) as a critical site where stigma was manifest and, indeed, where stigma was exacerbated on account of weak health systems. For mothers impacted by albinism, stigma was operationalized through health systems - whether by the stigmatizing attitudes and behaviours of healthcare providers, a lack of access to timely and quality health services, or a lack of health-related education and information about the cause and care of albinism.

The commonly mentioned first experience of stigma occurred as healthcare workers stigmatized the mother giving birth to a child with albinism, with judgmental comments, whispering and breaches of confidentiality, and even abandonment, as reflected in the narratives of Tishala, Amana, and Asha. A lesser standard of care was based on the stigmatizing beliefs these service providers held about albinism, and their resultant practices further stigmatized the mothers impacted by albinism. Stigmatizing attitudes and practices by healthcare providers against persons with albinism have been described by others (Baker et al. 2010; Imafidon 2017). Evidence on SDH reveals that such manifestations of stigma carry consequences for access to and quality of care, through pathways such as delays in future help-seeking, patient safety concerns, and poorer quality care (Knaak et al. 2017), all of which were evident for the mothers in our study. Stigma experienced within health facilities is described as "particularly egregious, negatively affecting people seeking health services at a time when they are most vulnerable" (Nyblade et al. 2019, p. 2).

A second way in which health systems differentially impacted these mothers and their children was in a lack of direct access to the health services required by persons with albinism that leads to health inequities (Mtenga et al. 2016). Decreased access, particularly to skin and vision clinics, was pronounced in rural settings and for those living in poverty. In our study, mothers in urban settings were more likely to have ongoing, regular access to a government-funded skin care clinic, compared to mothers in rural settings who were reliant on mobile outreach clinics delivered by NGOs.

A third way in which health systems as a SDH were particularly relevant for this population had to do with the lack of health information about the genetic causes of albinism, and the corresponding and appropriate care for children with albinism to prevent skin cancer and visual impairment. This vacuum was understandably filled by superstitions and myths, rooted in African ontology, which served as explanatory frames. To illustrate, the typical African person, especially in a rural community, understands a person with albinism as an other-than-human-being. The nature of such otherness may vary from one place to another, 
but what is clear is that such understanding of the being of persons with albinism (e.g., such as being a ghost, a white goat, a person who simply vanishes, and the like) obfuscates factual knowledge and accurate information about their being (Imafidon 2017). As recounted by Tishala, it was not until community-based education was offered in her village that she understood the genetic cause of albinism sufficiently to resist the stigma that was attached to the condition, and that community members began to view her differently, such that she moved from social exclusion to social inclusion. Similarly, de Groot et al. (2019) found that contact intervention, where people with albinism themselves are spokespersons educating communities about the condition, is an effective approach in stigma reduction. Access to health-related education and information are included as underlying determinants of health by the Committee on Economic, Social and Cultural Rights (UNECOSOC 2000; Chapman 2009). The findings of our study suggest that health-related education is urgently required to counter the stigma experienced by mothers impacted by albinism, as a pathway to thereby ensure their health and that of their children.

\subsubsection{Gender as a Social Determinant of Health}

Sen and Östlin (2007), in their Report on inequality to the World Health Organization Commission on Social Determinants of Health, conclude that gender relations of power constitute the root causes of gender inequality and are among the most influential SDH. Gender (and gender inequality) operated in complex ways in the everyday life for mothers impacted by albinism, and was sustained by deeply entrenched ontology.

First, problematic constructions of masculinity and femininity in the family context were interlaced with stigmatizing beliefs and practices. As evident in the preceding narratives, women were disproportionately blamed for the birth of a child with albinism as gendered speculations (accusation) about causation spring into effect (Reimer-Kirkham et al. 2019). Quickly following upon these speculations were concerns about family lineage and how its honour was stained by the birth of a child with albinism. Family is widely understood as a key site where gender is constructed and enacted (Helman and Ratele 2016) and for mothers impacted by albinism in Tanzania, this reality is crucial in understanding the health inequities that result. For the women in our study, their perceived worth plummeted upon birthing a child with albinism, and the internalized stigma that resulted is seen in Tishala's comment about not being "woman enough".

Taking a closer look at underpinning worldviews and ontology or theory of being that sustain such stigma, mothers with albinism are perceived to lack some ontological qualities necessary to be a full human person. An African "person" is often (especially in rural areas) thought to be caused into being through the rebirth of an ancestor, or the action of a supernatural benevolent force, such as a father or a mother or gifting from God. A mother or a person with albinism is thought to be ontologically caused into being due to some wrongdoing of the bearer of the child (which is always a woman) such as infidelity, or because of the punitive measures meted out on a lineage or a person by supernatural forces due to past deeds. Hence, a mother with albinism is ontologically excluded from enjoying the rights and privileges other persons enjoy for lacking the qualities that others have, qualities that are culturally entrenched and imposed. Beyond this, mothers with albinism face peculiar challenges in recent times based on the claim by witchdoctors that sexual relations with a girl or woman with albinism could cure HIV and AIDS (Imafidon 2019). Such a hideous claim merely emphasizes the fact that women with albinism are seen more as tools for some teleological purposes rather than as full human persons deserving to be treated 
as such. Moreover, mothers of children with albinism suffer from an ontology of exclusion because they are seen as failing to fulfil their ontologically imposed duty of giving birth to a full human person in the African context.

Second, these constructions of gendered stigma carry real consequences. Gender-based violence and abandonment were experienced by many of the mothers in our study. Gender inequality meant that for many they were without resources, power, and control, while being burdened with full responsibility for the welfare of their children. This finding is well documented (Heymann et al. 2019). Often abandoned by their partners, in-laws, and communities, the mothers in our study faced high levels of food insecurity and poverty, while vigilant to protect their children from attacks. Again, a contextualized, ontological understanding is necessary to appreciate the gravity of the social stigma experienced. In communal societies such as Tanzania, to be shunted away by a husband and one's in-laws means one is ostracized and devalued in the very community in which one's identity and being were knitted (Imafidon 2017). A degree of patriarchal opportunism was evident, as a deeply-rooted norm in African (particularly rural) communities, which implies,

... taking advantage of, and exploiting, the inherent quality of, or ability to, care, the maternal tenderness and affection of African women by African men. Patriarchal opportunism...begins with the recognition of African women as the pillar of care and wellbeing of the African community and then proceeds for several reasons to the exploitation of this ontological fact about African women in a manner that is draining, demeaning and abusive to African women. (Imafidon 2018, pp. 173-174)

Therefore, everyday living in a typical African community reveals that many African men are patriarchal opportunists who refuse to assist their wives, sisters and mothers in, for instance, home chores, and physically/emotionally nurturing and caring for the children. As a result, the husband or partner of a woman who gave birth to a child with albinism is a patriarchal opportunist if he shifts all the blame of bearing a child with albinism simply because it is the woman that nurtures the child in her body (womb) and nurtures and cares for the child in her post-womb stage of life.

Third, for many mothers in our study, mamas' groups became a lifeline to social inclusion and subsistence. Through the lens of gender as a SDH, the success of these groups can be seen as sites of resistance and agency, where mothers impacted by albinism came to recognize the stigma placed on them and, through finding common experience and new knowledges, grew to resist this stigma. Gaining means to support themselves and their children resulted in agency, that sense of empowerment and an ability to incrementally challenge structural barriers. This finding is supported by evidence of empowerment when comparing pre and post engagement with women's self-help groups (Hay et al. 2019; Sarania 2015), and research that has shown women's economic empowerment as one factor in the shift of attitudes toward greater gender equality (Heymann et al. (2019). Multilevel strategies to challenge gender inequality are needed, including support to women's organizations.

\subsection{Stigma and a Human Rights Approach}

The human rights approach to the situation of persons with albinism has increased in the last decade (UNGA 2019b). In context of women impacted by albinism, the approach has been eminent in recent academic scholarship and in several international and regional responses to the situation (African Committee of Experts on the Rights and Welfare of 
the Child (ACERWC) 2016; Ojilere and Saleh 2019; UN Committee on the Elimination of Discrimination against Women (CEDAW) 2014, 2015, 2016a, b; UN Committee on the Rights of Persons with Disabilities (CRPD) 2015, 2016a, b; UNGA 2017b). It is reasonable to deduce the growing human rights response is a reaction to the physical attacks and their root causes including stigma. The human rights approach has strong accountability principles, laying the principal duty of protection of persons on the State (UNGA 1998) who ought to intervene, in the wake of human rights violation, including through legislation, policy and specific measures particular to the violations in question. The human rights approach sets norms, standards and prohibitions. It also recognizes the interdependence of rights. Therefore, the lack of health information and abandonment experienced by mothers in this study is highly likely to leave them and their children vulnerable to poverty and physical violence. The human rights approach is built on the principle of universality, such that all rights recognized in the Universal Declaration of Human Rights (UDHR) (UNGA 1948) transcend cultural norms and ontologies where these appear to be in conflict with human rights. The approach also gives principal place to the right to participation of beneficiaries of interventions (UN Office of the High Commissioner for Human Rights (OHCHR) 2011) and in all interventions, prioritizes understanding the context where the violations have occurred and the human right is being applied, including understanding structural dynamics, cultural norms, and customs. Finally, and perhaps most central to the human rights approach and this study, is the principle of, and the right to equality and non-discrimination.

The principle of equality and non-discrimination is a primordial human rights tool for addressing and intervening in the face of inequalities, inequities and stigma such as experienced by these mothers. The principle is grounded in the UDHR and threads through other international human rights law notably the Convention on the Elimination of all forms of Discrimination against Women (CEDAW) (UNGA 1978) and in particular, the Convention on the Rights of Persons with Disabilities (CRPD) (UNGA 2007). The latter provides a broader basis for applying the human rights approach to the situation of these mothers because their experience is triggered and sustained by the condition of albinism. Moreover, the CRPD's broad integration of the rights of people with disabilities their family members, gender in the context of multiple and intersecting discrimination as seen in the above cases, makes it the most thorough instrument for assessing the situation of women impacted by albinism.

The violation of the right to equality and non-discrimination is not only a violation of a fundamental right, but also negatively impacts the reality and perception of their dignity (Ojilere and Saleh 2019). In addition, the negative stereotyping, and stigmatization as well as prejudices they encountered are also harmful to the perception of their being equal in rights among others in the community (UNCRPD 2018, para. 7).

All the women in this study experienced human rights violations centred on the absence of the enjoyment of the right to equality and non-discrimination. These include the right to not be discriminated against on the basis of gender, and the right to not be discriminated against on the basis of impairment ("disability"). They, and their children, also face various barriers to enjoyment of the right to health due to uninformed and unresponsive health professionals. All were stigmatized in the absence of specific measures to prevent and remedy the foregoing violations.

Since Tanzania has ratified the CRPD and engages the treaty in the context of persons with albinism, and the government of Tanzania has a duty to prohibit all discrimination (UNCRPD 2018, Article 5 (2)), the question is why mothers impacted by albinism experience multiple and intersecting inequality and discrimination? It is proposed that the reason 
lies in a failure to implement formal equality in tandem with a failure to carry out measures to drive substantive equality which are particularly necessary in the context of a patriarchy steeped in culturally entrenched systems that run contrary to human rights standards.

Formal equality seeks to combat direct discrimination by treating persons in a similar situation similarly. It may help to combat negative stereotyping and prejudices, but it cannot offer solutions for the "dilemma of difference", as it does not consider and embrace differences among human beings. Substantive equality, by contrast, also seeks to address structural and indirect discrimination and takes into account power relations. It acknowledges that the "dilemma of difference" entails both ignoring and acknowledging differences among human beings in order to achieve equality.

(UNCRPD 2018, para. 10)

For formal and substantive equality to penetrate parallel systems that appear to run counter to human rights principles, they must be accompanied by formal measures such as "effective legal remedies and sanctions in relation to intersectional discrimination in civil, administrative and criminal proceedings" (UNCRPD 2018, para. 22), including protection from any acts of discrimination carried out by private entities, but also "specific measures" (UNCRPD 2018, para. 28). These measures accelerate equality and provide advantages to a certain underrepresented or marginalized group. While they are usually temporary, they can also be permanent "depending on context and circumstances, including by virtue of a particular impairment or the structural barriers of society" (UNCRPD 2018, para. 28).

The most prevalent specific measures recommended to Tanzania by human rights mechanisms have included public education and awareness-raising, broadly stated, and therefore reasonably inclusive of health education information. This recommendation has been repeatedly made to Tanzania in various human rights review and accountability mechanisms such as the Universal Periodic Review (UPR), a peer-review mechanism established by the UN Human Rights Council as well as mechanisms and systems at the international (UNGA 2013; UNCRPD 2017) and regional levels (ACERWC 2016; African Commission on Human and Peoples' Rights (ACHPR) 2013; Pan-African Parliament (PAP) 2019). Tanzania has undergone two UPR cycles to date (UNGA 2011, 2016) during which recommendations made to and supported or noted by Tanzania (using the keyword *albin in UPR-Info database), showed repeated recommendations on awareness-raising and public education made by various Member States worldwide, including Botswana, Canada, Germany, Haiti, Honduras, Sierra Leone, and Uganda (UNGA 2011, 2016). It is evident, in the face of stigmatizing ontologies on the condition of albinism and persons directly impacted, that such measures are necessary. The strategy of effective implementation of such public education, often absent in most of these recommendations, could be informed with the particular findings of this study.

\section{Implications}

The implication for both government and NGOs intervening on the situation of persons with albinism is the strategic prioritization of women impacted by albinism, and their family members in public education and awareness raising. Health workers, midwives in particular, ought to be simultaneously and regularly targeted for health education on albinism, either through stand-alone initiatives or as part of larger modules on disability and gender. Where the society is fundamentally patriarchal and stigma is fostered 
by cultural ontologies, health education and information on albinism should also target key custodians of culture in the community where the child with albinism is born. The absence of health information when a child with albinism is born puts mother and child at high risk of stigma resulting in multiple and intersecting discrimination. Access to health information can protect them and their children, their livelihood and prevent poverty. It can also protect their children from vulnerability to attack. It can inject empowerment and resilience in the mother of children with albinism, and foster social inclusion among her family members and her community.

The findings of this study point to the need for increased effort and support to replicate and enrich peer groups of mothers impacted by albinism. These groups are reservoirs of resilience for such mothers, as well as a focal point for meaningful consultation and participation regarding relevant measures and interventions. Apart from NGOs, governments who are ultimate duty bearers in the right to health should invest in these programs through targeted, concrete measures. The particular impairment of albinism warrants specific, permanent measures to effectively and sustainably transform cultural norms and structures to bear universal human rights standards.

The study also carries implications for future scholarship, especially in regard to what community responses, interventions such as peer-support groups, and government policies and resources are most effective in mitigating the detrimental effects of stigma on mothers impacted by albinism. Future research is also needed to understand the experiences of fathers and siblings impacted by albinism and stigma. Our analysis exemplifies the deepened insights afforded by approaches, such as the Health Stigma and Discrimination Framework, which emphasize broader social, cultural, political and economic forces that structure stigma (Stangl et al. 2019).

\section{Conclusion}

In summary, the daily lives of mothers impacted by albinism were riddled with subjective, social, and structural stigma, which was exacerbated by weak SDH. The cumulative effects of these intersections led to deeper poverty and unstable incomes, food insecurity, unstable housing and shelter, and social exclusion. On top of the precarity of day-to-day survival, mothers were faced with the near impossible imperative of heightened vigilance to protect their children from stigma, discrimination, and attacks. Mothers in this study were disproportionately impacted by health-related stigma, resulting in drastically reduced quality of life, heightened morbidity (mental health challenges, skin cancer, chronic conditions), and deepened deprivation. The pervasive undermining of the humanity of mothers impacted by albinism, and their experience of stigma based on albinism, gender, with the social and economic consequences (Sen and Östlin 2007) point to the urgent need for a comprehensive framework of response which can be found in the human rights approach. A concrete avenue to de-stigmatization of mothers impacted by albinism exists by the application of principles of human rights, particularly equality and non-discrimination; contextual analysis of cultural dynamics including relevant ontology; meaningful participation of rights-claimants, such as peer groups of mothers; and accountability of governments and their obligation to ensure access to health information as a key social determinant of the right to health. 
Acknowledgements We are indebted to the mothers and stakeholders who participated in the study, Mothering, albinism, and human rights in Africa: Mapping patterns of resilience at the juncture of gender, colourism, and religion (Funding: Social Sciences and Humanities Research Council Canada \#435-2019-1120; Principal Applicant: Sheryl Reimer-Kirkham). Thank-you to the NGOs who have supported this project (Under the Same Sun, Standing Voice) and contributed in countless ways (such as providing for the logistics of transportation and interpreters, facilitating REB clearance, recruitment, data collection, and knowledge translation). We are grateful for expert cultural liaison Jane Waithera. The commitment of the project staff, Emma Strobell (Project Coordinator, Trinity Western University) and Meghann Buyco (Research Assistant, MSN student, Trinity Western University) for the cause of human rights protection for persons with albinism is heartwarming. With acknowledgement of the project team: Sheryl Reimer-Kirkham, Barbara Astle, Ikponwosa Ero, Lori Beaman, Bonny Ibhawoh, Elvis Imafidon, Jennifer Kromberg, Berthasia Ladislaus, Nomasonto Mazibuko, Innocentia Mgijima-Konopi, Kristi Panchuk, Perpetua Senkora, Sonya Sharma, Wisdom Tettey, Boateng Wiafi. Thank you to Ester Rwela for assisting with research ethics clearance and other logistics in Tanzania.

\section{Compliance with Ethical Standards}

Conflict of interest On behalf of all authors, the corresponding author states that there is no conflict of interest.

Open Access This article is licensed under a Creative Commons Attribution 4.0 International License, which permits use, sharing, adaptation, distribution and reproduction in any medium or format, as long as you give appropriate credit to the original author(s) and the source, provide a link to the Creative Commons licence, and indicate if changes were made. The images or other third party material in this article are included in the article's Creative Commons licence, unless indicated otherwise in a credit line to the material. If material is not included in the article's Creative Commons licence and your intended use is not permitted by statutory regulation or exceeds the permitted use, you will need to obtain permission directly from the copyright holder. To view a copy of this licence, visit http://creativecommons.org/licenses/by/4.0/.

\section{References}

Affram, A. A., Teye-Kwadjo, E., \& Gyasi-Gyamerah, A. A. (2019). Influence of social stigma on subjective well-being of persons with albinism in Ghana. Journal of Community and Applied Social Psychology, 29(4), 323-335. https://doi.org/10.1002/casp.2403.

African Commission on Human and Peoples' Rights. (2013). 263 Resolution on the prevention of attacks and discrimination against persons with albinism (ACHPR/Res.263(LIV)2013). Retrieved September 13, 2020 from https://www.achpr.org/sessions/resolutions?id=283.

African Committee of Experts on the Rights and Welfare of the Child (ACERWC). (2016). Report on investigative mission on the situation of children with albinism in temporary holding shelters-Tanzania [PDF]. Addis Ababa: ACERWC. Retrieved September 13, 2020 from https://www.refworld.org/pdfid 15811f7234.pdf.

Aluko-Olokun, B., Olaitan, A. A., Morgan, R. E., Oginni, F. O., Aluko-Olokun, O. A., Ibukun-Obaro, O., et al. (2016). Is there an association between African national HIV prevalence values and socioeconomic status of their albino populations? HIV and AIDS Review, 15(2), 73-79. https://doi. org/10.1016/j.hivar.2016.02.001

Aquaron, R., Djatou, M., \& Kamdem, L. (2009). Sociocultural aspects of albinism in sub-Saharan Africa: Mutilations and ritual murders committed in east Africa (Burundi and Tanzania). Medecine Tropicale: Revue du Corps de Sante Colonial, 69(5), 449-453.

Attama, C. M., Uwakwe, R., Onyeama, G. M., \& Igwe, M. N. (2015). Psychiatric morbidity among subjects with leprosy and albinism in south east Nigeria: A comparative study. Annals of Medical and Health Sciences Research, 5(3), 197-204.

Baker, C., Lund, P., Nyathi, R., \& Taylor, J. (2010). The myths surrounding people with albinism in South Africa and Zimbabwe. Journal of African Cultural Studies, 22(2), 169-181.

Blanchet Garneau, A., Browne, A. J., \& Varcoe, C. (2019). Understanding competing discourses as a basis for promoting equity in primary health care. BMC Health Services Research, 19, Article 764. 
Bradbury-Jones, C., Ogik, P., Betts, J., Taylor, J., \& Lund, P. (2018). Beliefs about people with albinism in Uganda: A qualitative study using the common-sense model. PLoS ONE, 13(10), e0205774. https:// doi.org/10.1371/journal.pone.0205774

Brilliant, M. H. (2015). Albinism in Africa: A medical and social emergency. International Health, 7(4), 223-225.

Brocco, G. (2015). Labeling albinism: Language and discourse surrounding people with albinism in Tanzania. Disability \& Society, 30(8), 1143-1157.

Brocco, G. (2016). Albinism, stigma, subjectivity and global-local discourses in Tanzania. Anthropology and Medicine, 23(3), 229-243.

Burke, J. (2015). Colourism as an intra-racial phenomenon: The case of Tanzania. In African studies association of Australia and the Pacific (AFSAAP) 37th annual conference. Dunedin, NZ. Retrieved September 13, 2020 from https://pdfs.semanticscholar.org/50cc/d4a6c28bc047e1a1dbf5159bec52cb56915 d.pdf.

Canadian Coalition for Global Health Researchers (CCGHR). (2015). CCGHR principles of global health research. Author.

Chapman, A. R. (2009). Globalization, human rights, and the social determinants of health. Bioethics, 23(2), 97-111.

Clement, S., Schauman, O., Graham, T., Maggioni, F., Evans-Lacko, S., Bezborodovs, N., et al. (2015). What is the impact of mental health-related stigma on help-seeking? A systematic review of quantitative and qualitative studies. Psychological Medicine, 45(1), 11-27.

Corrigan, P. W. (Ed.). (2014). The stigma of disease and disability: Understanding causes and overcoming injustices. Washington, DC: American Psychological Association.

Cruz-Inigo, A. E., Ladizinski, B., \& Sethi, A. (2011). Albinism in Africa: Stigma, slaughter and awareness campaigns. Dermatologic Clinics, 29(1), 79-87.

de Groot, T., Meurs, P., \& Jacquet, W. (2019). The effect of contact interventions on the stigma of people with albinism in Tanzania. Journal of Visual Impairment and Blindness, 113(5), 464-469.

Franklin, A., Lund, P., Bradbury-Jones, C., \& Taylor, J. (2018). Children with albinism in African regions: Their rights to 'being' and 'doing'. BMC International Health and Human Rights, 18(2), 1-8.

Goffman, E. (1963). Stigma: Notes on the Management of Spoiled Identity. New York: Simon \& Schuster.

Grønskov, K., Ek, J., \& Brondum-Nielsen, K. (2007). Oculocutaneous albinism. Orphanet Journal of Rare Diseases, 2(1), 43.

Hatzenbuehler, M. L. (2016). Structural stigma and health inequalities: Research evidence and implications for psychological science. American Psychology, 71(8), 742-751. https://doi.org/10.1037/amp0000068

Hay, K., McDougal, L., Percival, V., Henry, S., Klugman, J., Wurie, H., et al. (2019). Disrupting gender norms in health systems: Making the case for change. The Lancet, 393(10190), 2535-2549. https://doi. org/10.1016/S0140-6736(19)30648-8

Helman, R., \& Ratele, K. (2016). Everyday (in) equality at home: Complex constructions of gender in South African families. Global Health Action, 9(1), 31122.

Heymann, J., Levy, J. K., Bose, B., Ríos-Salas, V., Mekonen, Y., Swaminathan, H., Omidakhsh, N., Gadoth, A., Huh, K., Greene, M. E., \& Darmstadt, G. L. (2019). Improving health with programmatic, legal, and policy approaches to reduce gender inequality and change restrictive gender norms. The Lancet, 393(10190), 2522-2534. DOI https://doi.org/10.1016/S0140-6736(19)30656-7.

Hong, E., Zeeb, H., \& Repacholi, M. (2006). Albinism in Africa as a public health issue. BMC Public Health, 6(1), 212-217.

Imafidon, E. (2017). Deling with the other between the ethical and the moral: Albinism on the African continent. Theoretical Medicine and Bioethics, 38(2), 163-177.

Imafidon, E. (2018). Is the African feminist moral epistemology of care fractured? Synthesis Philosophica, $33(1), 165-177$.

Imafidon, E. (2019). African philosophy and the otherness of albinism: White skin, black race. Milton Park: Routledge.

International Federation of Red Cross and Red Crescent Societies. (2009). Through albino eyes: The plight of albino people in Africa's Great Lakes region and a Red Cross response. Geneva: International Federation of Red Cross and Red Crescent Societies. Retrieved September 13, 2020 from https://www.ifrc. org/Global/Publications/general/177800-Albinos-Report-EN.pdf.

Jootun, D., McGhee, G., \& Marland, G. (2009). Reflexivity: Promoting rigour in qualitative research. Nursing Standard, 23(23), 42-46. https://doi.org/10.7748/ns2009.02.23.23.42.c6800.

Kenyon, K. H., Forman, L., \& Brolan, C. E. (2018). Deepening the relationship between human rights and the social determinants of health: A focus on indivisibility and power (Editorial). Health and Human Rights Journal, 20(2), 1-9. 
Kiprono, S. K., Joseph, L. N., Naafs, B., \& Chaula, B. M. (2012). Quality of life and people with albinism in Tanzania: More than only a loss of pigment. Scientific Reports, 1, 2-83.

Knaak, S., Mantler, E., \& Szeto, A. (2017). Mental illness-related stigma in healthcare: Barriers to access and care and evidence-based solutions. In Healthcare management forum (Vol. 30, No. 2, pp. 111116). Sage CA: Los Angeles, CA: SAGE Publications.

Kromberg, J., \& Manga, P. (2018). Albinism in Africa: Historical, geographic, medical, genetic, and psychosocial aspects. Cambridge: Academic Press.

Kromberg, J., Manga, P., \& Kerr, R. (2020). Children with oculocutaneous albinism in Africa: Characteristics, challenges and medical care. South African Journal of Child Health, 14(1), 50-54.

Kromberg, J., Zwane, E. M., \& Jenkins, T. (1987). The response of black mothers to the birth of an albino infant. American Journal of Diseases of Children, 141(8), 911-916.

Lincoln, Y. S., \& Guba, E. G. (1985). Naturalistic inquiry. Thousand Oaks: SAGE.

Link, B. G., \& Phelan, J. C. (2001). Conceptualizing stigma. Annual Review of Sociology, 27(1), 363-385.

Link, B. G., \& Phelan, J. C. (2006). Stigma and its public health implications. The Lancet, 367(9509), 528-529.

Lund, P. M., \& Roberts, M. (2018). Prevalence and population genetics of albinism: Surveys in Zimbabwe, Namibia, and Tanzania. In J. Kromberg \& P. Manga (Eds.), Albinism in Africa (pp. 81-98). London: Academic Press.

Maluwa, M., Aggleton, P., \& Parker, R. (2002). HIV-and AIDS-related stigma, discrimination, and human rights: A critical overview. Health and Human Rights, 6, 1-18.

Mtenga, S., Masanja, I. M., \& Mamdani, M. (2016). Strengthening national capacities for researching on social determinants of health $(\mathrm{SDH})$ towards informing and addressing health inequities in Tanzania. International Journal for Equity in Health, 15(1), 23.

Muromi, S. (2014). Violence against persons with albinism and older women: Tackling witchcraft accusations in Tanzania.. International Journal of Education and Research, 2(6), 323-338.

Mutasa, F. L. (2013). An investigation into the psychosocial implications of oculocutaneous albinism: A case study of the Manicaland albino association (Master's thesis). University of Zimbabwe. Retrieved September 13, 2020 from https://pdfs.semanticscholar.org/da60/0563758a4967e6a18f58d76e3c425b abe651.pdf.

Nyblade, L., Stockton, M. A., Giger, K., Bond, V., Ekstrand, M. L., Lean, M., et al. (2019). Stigma in health facilities: Why it matters and how we can change it. BMC Medicine, 17(1), 25.

Nyangweso, M., \& Olupona, J. (2020). Religion in gender-based violence, immigration, and human rights. London: Routledge.

Ojilere, A., \& Saleh, M. M. (2019). Violation of dignity and life: Challenges and prospects for women and girls with albinism in sub-Saharan Africa. Journal of Human Rights and Social Work, 4(3), 147-155.

Okoro, A. N. (1975). Albinism in Nigeria 1: A clinical and social study. British Journal of Dermatology, 92(5), 485-492.

Olupona, J. (2014). African religions: A very short introduction. Oxford: Oxford University Press.

Pan-African Parliament (May 17, 2019). Resolution on concrete measures for the promotion and protection of the rights of persons with albinism in Africa. Retrieved September 14, 2020 from https://www.chr. up.ac.za/images/researchunits/dgdr/documents/pap/Resolution\%20on\%20Albinism\%20.pdf.

Parker, R. (2012). Stigma, prejudice and discrimination in global public health. Cadernos de Saúde Pública, 28, 164-169.

Phatoli, R., Bila, N., \& Ross, E. (2015). Being black in a white skin: Beliefs and stereotypes around albinism at a South African university. African Journal of Disability, 4(1), 106.

Polit, D. F., \& Beck, C. T. (2017). Qualitative research design and approaches. In Nursing Research: Generating and assessing evidence for nursing practice (10th ed.) (pp. 463-490). Philadelphia: Wolters Kluwer.

Possi, M. K. (1998). Stigma and people with disability: A review of stigma attached to people with albinisms. International Journal of Special Education, 13(2), 511-531.

Reimer-Kirkham, S., Astle, B., Ero, I., Panchuk, K., \& Dixon, D. (2019). Albinism, spiritual and cultural practices, and implications for health, healthcare, and human rights: A scoping review. Disability \& Society, 34(5), 747-774.

Salewi, D. H. (2011). The killing of persons with albinism in Tanzania: A social-legal inquiry (LLM dissertation). University of Pretoria. Retrieved September 13, 2020 from https://repository.up.ac.za/handl e/2263/18645.

Sarania, R. (2015). Impact of self-help groups on economic empowerment of women in Assam. International Research Journal of Interdisciplinary and Multidisciplinary Studies, 1(1), 148-159.

Sen, G., \& Östlin, P. (2007). Unequal, unfair, ineffective and inefficient, Gender inequity in health: Why it exists and how we can change it final [PDF]. Retrieved September 13, 2020 from https://www.who.int/socia 1_determinants/resources/csdh_media/wgekn_final_report_07.pdf. 
Stangl, A. L., Earnshaw, V. A., Logie, C. H., van Brakel, W., Simbayi, L. C., Barré, I., \& Dovidio, J. F. (2019). The health stigma and discrimination framework: A global, crosscutting framework to inform research, intervention development, and policy on health-related stigmas. BMC Medicine, 17(1), 31.

Stangl, A. L., Lloyd, J. K., Brady, L. M., Holland, C. E., \& Baral, S. (2013). A systematic review of interventions to reduce HIV-related stigma and discrimination from 2002 to 2013: How far have we come? Journal of the International AIDS Society, 16, 18734.

Stronks, K., Toebes, B., Hendriks, A., Ikram, U., \& Venkatapuram, S. (2016). Social justice and human rights as a framework for addressing social determinants of health: Final report of the task group on equity, equality, and human rights (Review of social determinants of health and the health divide in the WHO European region). Copenhagen: WHO. Retrieved September 13, 2020 from http://www.euro.who.int/_ data/assets/pdf_file/0006/334356/HR-task-report.pdf?ua=1.

The United Republic of Tanzania. (2014). Basic demographic and socio-economic profile [PDF]. Retrieved September 13, 2020 from https://www.tanzania.go.tz/egov_uploads/documents/NATIONAL_SOCIO -ECONOMIC_PROFILE_sw.pdf.

The United Republic of Tanzania. (2016). Disability monograph [PDF]. Retrieved September 13, 2020 from http://www.rodra.co.za/images/countries/tanzania/research/Tanzania\%20Disability\%20Monograph\%20 2016.pdf.

United Nations (2015). Transforming our world: The 2030 agenda for sustainable development. Retrieved September 13, 2020 from https://sustainabledevelopment.un.org/post2015/transformingourworld/publication.

United Nations Convention on the Elimination of All Forms of Discrimination against Women. (2014). Concluding observations on the combined initial and second periodic reports of Swaziland (CEDAW/C/SWZ/ CO/1-2). Retrieved September 13, 2020 from https://undocs.org/en/CEDAW/C/SWZ/CO/1-2.

United Nations Convention on the Elimination of All Forms of Discrimination against Women. (2015). Concluding observations on the seventh periodic report of Malawi (CEDAW/C/MWI/CO/7). Retrieved September 13, 2020 from https://undocs.org/en/CEDAW/C/MWI/CO/7.

United Nations Convention on the Elimination of All Forms of Discrimination against Women. (2016a). Concluding observations on the combined seventh and eighth periodic reports of the United Republic of Tanzania (CEDAW/C/TZA/CO/7-8). Retrieved September 13, 2020 from https://undocs.org/en/CEDAW/C/ $\mathrm{TZA} / \mathrm{CO} / 7-8$.

United Nations Convention on the Elimination of All Forms of Discrimination against Women. (2016b). Concluding observations on the combined fifth and sixth periodic reports of Burundi (CEDAW/C/BDI/CO/66). Retrieved September 13, 2020 from https://undocs.org/en/CEDAW/C/BDI/CO/5-6.

United Nations Convention on the Rights of Persons with Disabilities. (2015). Concluding observations on the initial report of Kenya (CRPD/C/KEN/CO/1). Retrieved September 13, 2020 from https://undocs.org/ $\mathrm{CRPD} / \mathrm{C} / \mathrm{KEN} / \mathrm{CO} / 1$.

United Nations Convention on the Rights of Persons with Disabilities. (2016a). Concluding observations on the initial report of Ethiopia (CRPD/C/ETH/CO/1). Retrieved September 13, 2020 from https://undocs.org/ $\mathrm{CRPD} / \mathrm{C} / \mathrm{ETH} / \mathrm{CO} / 1$.

United Nations Convention on the Rights of Persons with Disabilities. (2016b). Concluding observations on the initial report of Uganda (CRPD/C/UGA/CO/1). Retrieved September 13, 2020 from https://undocs.org/ $\mathrm{CRPD} / \mathrm{C} / \mathrm{UGA} / \mathrm{CO} / 1$.

United Nations Convention on the Rights of Persons with Disabilities. (2017). Committee on the Rights of Persons with Disabilities: Communication No. 22/2014 (CRPD/C/18/D/22/2014). Retrieved September 13, 2020 from https://www.ohchr.org/Documents/HRBodies/CRPD/CRPD-C-18-DR-22-2014.pdf.

United Nations Convention on the Rights of Persons with Disabilities. (2018). General comment on No. 6 (2018) on equality and non-discrimination(CRPD/C/GC/6). Retrieved September 13, 2020 from https:// undocs.org/CRPD/C/GC/6.

United Nations Economic and Social Council (UNECOSOC). (2000). General Comment No. 14 (2000) The right to the highest attainable standard of health (article 12 of the International Covenant on Economic, Social, and Cultural Rights) (E/C.12/2000/4). Retrieved September 13, 2020 from https://undoc s.org/E/C.12/2000/4.

United Nations General Assembly. (1948). Universal Declaration of Human Rights, 10 December, A/RES/217/ (III). Paris. Retrieved September 13, 2020 from https://undocs.org/A/RES/217(III).

United Nations General Assembly. (1978). Convention on the elimination of all forms of discrimination against women (CEDAW). Retrieved September 13, 2020 from https://www.ohchr.org/en/professionalinterest/ pages/cedaw.aspx.

United Nations General Assembly. (1998). Declaration on the right and responsibility of individuals, groups, and organs of society to promote and protect universally recognized human rights and fundamental freedoms. Retrieved September 13, 2020 from https://www.ohchr.org/en/professionalinterest/pages/rightandre sponsibility.aspx. 
United Nations General Assembly. (2007). Resolution adopted by the General Assembly on 13 December 2006: Convention on the Rights of Persons with Disabilities (CRPD) (A/RES/61/106). Retrieved September 13, 2020 from https://undocs.org/A/RES/61/106.

United Nations General Assembly. (2011). Report of the working group on the universal periodic review: United Republic of Tanzania (A/HRC/19/4). Retrieved September 13, 2020 from https://undocs.org/A/HRC/19/4.

United Nations General Assembly. (2013). Resolution adopted by the Human Rights Council 23/13: Attacks and discrimination against persons with albinism (A/HRC/RES/23/13). Retrieved September 13, 2020 from https://undocs.org/A/HRC/RES/23/13.

United Nations General Assembly. (2015). Resolution adopted by the general assembly on 25 September 2015, Transforming our world: The 2030 agenda for sustainable development (A/RES/70/1). Retrieved September 13, 2020 from https://undocs.org/A/RES/70/1.

United Nations General Assembly. (2016). National report submitted in accordance with paragraph 5 of the annex to human rights council resolution 16/21: United Republic of Tanzania (A/HRC/WG.6/25/TZA/1). Retrieved September 13, 2020 from https://undocs.org/A/HRC/WG.6/25/TZA/1.

United Nations General Assembly. (2017a). Report of the independent expert on the enjoyment of human rights by persons with albinism on her mission to the United Republic of Tanzania (A/HRC/37/57/Add.1). Retrieved September 13, 2020 from https://undocs.org/A/HRC/37/57/Add.1.

United Nations General Assembly. (2017b). Applicable international human rights standards and related obligations addressing the issues faced by persons with albinism: Report of the independent expert on the enjoyment of human rights by persons with albinism (A/72/131). Retrieved September 13, 2020 from https ://undocs.org/A/72/131

United Nations General Assembly. (2019a). Women and children impacted by albinism: Report of the independent expert on the enjoyment of human rights by persons with albinism (A/HRC/43/42). Retrieved September 13, 2020 from https://undocs.org/A/HRC/43/42.

United Nations General Assembly. (2019b). Round table on human rights and albinism: Seeking consensus and priorities on advocacy and research, Report of the Independent Expert on the enjoyment of human rights by persons with albinism (A/HRC/40/62/Add.2). Retrieved September 13, 2020 from https://undoc s.org/A/HRC/40/62/Add.2.

United Nations Office of the High Commissioner for Human Rights. (2011). Manual on human rights monitoring (HR/P/PT/7/Rev.1). Retrieved September 13, 2020 from https://www.ohchr.org/Documents/Publicatio ns/Chapter02-MHRM.pdf.

Under the Same Sun. (n.d.). Frequency of albinism/Rates of occurrence: North America, Europe, Africa, and Tanzania. Retrieved September 13, 2020 from https://underthesamesun.com/sites/default/files/Frequ ency\%20of\%20Albinism.pdf.

World Health Organization (WHO) Commission on Social Determinants of Health (CSDH) (2008). Closing the gap in a generation: Health equity through action on the social determinants of health. Retrieved September 13, 2020 from https://apps.who.int/iris/bitstream/handle/10665/43943/9789241563703_eng.pdf;jsess ionid=5A3C8A250CE97F575D3AE61E42F1D6FE? sequence $=1$.

World Health Organization (2020). Health systems. Retrieved September 13, 2020 from https://www.who. int/healthsystems/topics/equity/en/.

Dr. Sheryl Reimer-Kirkham is Dean and Professor of Nursing at Trinity Western University, Langley, Canada. Her research is in the area of plurality and equity in healthcare, at the intersections of religion, race, class, and gender, and she leads the Mothering and Albinism project. She teaches the interrelated fields of spirituality and health, health policy, knowledge translation, and nursing philosophy. She has received numerous recognitions for her scholarship, including Fellow of the Canadian Academy of Nursing; 2019 UBC School of Nursing Centenary Medal of Distinction; member of the Royal Society of Canada's College of New Scholars, Scientists and Artists; the Award of Excellence in Nursing Research by the College of Registered Nurses of British Columbia (CRNBC). She is author of Prayer as Transgression? The Social Relations of Prayer in Healthcare Settings (McGill-Queens University Press, 2020).

Dr. Barbara Astle is Associate Professor, \& Director of the Master in Science (MSN) program at Trinity Western University, Canada. Her research focuses on areas of global and planetary health, health equity, albinism and human rights, gender, and research literacy. Astle is a leader in global health education, research literacy, and her involvement in numerous national and international organizations. She was a recipient of the Excellence in Nursing Education Award by the Association of Registered Nurses in British Columbia, Canada (2017) acknowledging her research, education, and mentorship in global health. She is a founding member for the Women in Global Health (WGH) Canadian Chapter (2020). 
Ikponwosa Ero JD is a human rights lawyer appointed in 2015 as the inaugural United Nations (UN) Independent Expert on the Enjoyment of Human Rights by Person with Albinism. In January 2020 she coordinated the formation of the Albinism Global Alliance. She has advised organizations and governments around the world on human rights concerning persons with albinism. As the International Advocacy and Legal Officer for Under the Same Sun — an international organization with a focus on albinism-she developed strategic initiatives involving regional and international human rights mechanisms, prepared guiding documents, and oversaw the implementation of recommendations made by the UN and other human rights organizations. Ms Ero has authored numerous papers and articles, particularly with regards to applicable legal frameworks as well as the development and implementation of special measures to facilitate the enjoyment of human rights by persons with albinism.

Dr. Elvis Imafidon is Lecturer in the School of History, Religions and Philosophies at the School of Oriental and African Studies (SOAS), University of London, London. Formerly a lecturer with Ambrose Alli University in Nigeria, he specializes in comparative African philosophy and continental philosophy with specific interests in African ontology, African ethics, African epistemology, African philosophy of disability, philosophy and public health and alterity studies. He is author of African Philosophy and the Otherness of Albinism: White Skin, Black Race (Routledge 2019) and editor of Handbook of African Philosophy of Difference (Springer 2020).

Emma Strobell, Master of Science in Nursing (MSN) is Project Coordinator for the SSHRC funded project on mothering and albinism at Trinity Western University, Canada. Strobell's graduate research for her Masters focused on the experience of mothers who have children with albinism in Tanzania. She has continued to be involved with this funded project as it has expanded to other countries in Africa. Her research focuses on mothering, albinism, human rights, gender, and health equity. Her extensive clinical and teaching practice has focused on community health nursing in rural/remote communities in Canada's Northwest Territories as well as public health nursing in British Columbia. 